\title{
EXPERIÊNCIAS DE CONVIVÊNCIA NO SEMIÁRIDO MINEIRO: REFLEXÕES À LUZ DO "CANDEEIRO" E DOS CONCEITOS DE REGIÃO E REDES SOCIOTERRITORIAIS
}

\author{
Ludimila de Miranda Rodrigues Silva \\ Doutoranda em Geografia pela Universidade Federal de Minas Gerais, Instituto de Geociências, Pós-graduação \\ em Geografia, Belo Horizonte, MG, Brasil \\ ludimilarodrigues86@gmail.com
}

Nayhara Freitas Martins Gomes Doutoranda em Geografia pela Universidade Federal de Minas Gerais, Instituto de Geociências, Pós-graduação em Geografia, Belo Horizonte, MG, Brasil nayhara martins@yahoo.com.br

\begin{abstract}
RESUMO
O semiárido brasileiro é uma região caracterizada pela vulnerabilidade climática e por longos períodos de estiagem. Nela, há décadas atrás, observavam-se baixos índices de desenvolvimento local. Estes fatores combinados, ainda hoje, contribuem para a manutenção dos discursos que consideram o semiárido, "uma região-problema". Contudo, a partir da década de 1980, surgiram propostas de convivência com a seca, através de olhares atentos que entendiam que a seca não representava um entrave à reprodução das famílias rurais. Neste sentido, ao longo do presente estudo, se enfatiza que a convivência com o semiárido deve ser feita através de um conjunto de medidas orientadas pelos atores sociais que vivem nesta região, capazes de formular projetos sob a ótica dos saberes e práticas locais. Nessa perspectiva, buscou-se analisar as relações entre esses discursos com os conceitos de região e de rede socioterritorial. Ademais, procurou-se investigar a realidade do Semiárido, no contexto do Estado de Minas Gerais e as práticas de convivência, através da análise descritiva de informações divulgadas pelo Boletim Candeeiro no período de 2009 a 2017. Por meio desta análise foi possível identificar inúmeras ações de convivência com a seca que garantiram melhorias para a vida rural, alcançadas, sobretudo, pela atuação de redes conformadas por entidades diversas.
\end{abstract}

Palavras-chave: Boletim Candeeiro. Região. Redes Socioterritoriais. Convivência Semiárido Mineiro.

\section{EXPERIENCES OF COEXISTENCE IN THE SEMIÁRID MINEIRO: REFLECTIONS TO THE LIGHT OF THE "CANDEEIRO" AND THE CONCEPTS OF REGION AND SOCIOTERRITORIAL NETWORKS}

\begin{abstract}
The Brazilian semi-arid is a region marked by climate vulnerability and by very long dry periods. At this region, decades ago, low composite indexes draw attention. These factors combined, nowadays, contribute for maintenance of speeches considering the semiarid as one "trouble-region". Notwithstanding, since 1980, new proposals with how to live with drought started to appear through new ways of thinking that believed thedrought does not represent any kind of obstacles to rural's family reproduction. This paper emphasized that the relation with the semiarid must be done using oriented precautins through through the social agentes living in this region who are capable of developing projects under the perspectiveof local knowledge and practices. In this perspective, the study analyzed the relation between the speeches with regional concepts and socioterritorial nets. Besides, it investigated the Semiarid reality inside Minas Gerais' State and the coexistence practices by a descriptive analysis from data published by the BOLETIM CANDEEIRO from 2009 to 2017. By means of this, became possible to identify several actions of living with drought which granted better results to rural life, achieved, mainly, by the actions of net composed by several entities.
\end{abstract}

Keywords: Boletim Candeeiro. Region. Socio-territorial Nes. Coexistence. Mineiro Semiarid. 


\section{INTRODUÇÃO}

A ciência geográfica desde o século XIX vem ganhando complexidade dado a produção de conhecimentos teóricos e empíricos acerca do estudo de fenômenos e das espacialidades a estes associados. Nesta seara, o pensamento geográfico fundamentou-se por categorias de análise (espaço, região, território, lugar e paisagem) que permitiram clarificar o emaranhado de relações às quais o saber geográfico detém interesse. Ao longo do tempo, essas categorias no âmbito do conhecimento científico adquiriram formas e percepções distintas, a ponto de não serem de uso exclusivamente da Geografia. Nesse sentido, para além das concepções conceituais científicas, tais categorias refletem ainda diversos processos que estão intimamente ligados às imbricações políticas, econômicas e sociais.

O conceito de região, por exemplo, historicamente destaca-se como uma referência fortemente vinculada ao recorte espacial de domínio central de uma determinada potência/instituição: como o Império Romano; a Igreja Católica (já no século IV d.C), e que no Feudalismo, concebia a base regional como um instrumento de definição da sua hierarquia administrativa; as regiões dos EstadosNacionais militarizados no Estado Moderno (séc. XVIII) e etc. Na contemporaneidade, a redefinição do papel do Estado estimula o ressurgimento das questões regionais vinculadas ainda com outras centralidades que senão as entidades governamentais, incitando inclusive movimentos de confronto entre nacionalistas e regionalistas. A região, no contexto atual, passa, nesse sentido, a vincular-se fortemente a fatores e elementos de identificação do povo com seus lugares de vivência e com sua identidade regional. Posto isso, para além das divisões administrativas de micro e mesorregiões que prevalecem como meio de governar e ordenar grandes espaços, o conceito de região agrega ainda diferentes sentidos e significados que dizem muito sobre os fenômenos e as dinâmicas sociais em determinados recortes regionais, como é o caso da própria concepção de "semiárido" que no Norte de Minas e em algumas microrregiões do Vale do Jequitinhonha, possui uma correspondência identitária muito mais expressiva do que as outras divisões administrativas utilizadas pelo Estado.

Neste contexto, este trabalho objetiva discutir a concepção regional do semiárido mineiro, destacando suas implicações frente às políticas públicas e dinâmicas socioespaciais de consolidação das redes socioterritoriais das populações e entidades inseridas neste contexto. Para tal, foram sistematizadas informações acerca das práticas e ações da Articulação do Semiárido (ASA), divulgadas por meio do boletim "O Candeeiro" focalizando a troca de experiências entre os agricultores que convivem com o semiárido mineiro. Nesse sentido, foram levantados 113 boletins referentes ao Estado de Minas Gerais entre o período de 2009 a 2017, sobre os quais foram realizadas análises no intuito de verificar a configuração de "redes socioterritoriais" neste estado identificando a integração entre entidades, projetos, parceiros, comunidades e suas experiências.

Apesar do seu aporte regional - do semiárido - a ASA busca compreendê-lo não como uma região homogênea, uniforme e de limites totalmente rígidos, mas como uma diversidade populacional e ambiental, dinamizada por suas singularidades locais em torno de uma problemática comum, as limitações hídricas. Nesse sentido, seus projetos e ações atuam por meio da interação e articulação entre entidades governamentais, organizações não-governamentais, grupos religiosos, Sindicato dos Trabalhadores Rurais, associações comunitárias e etc.

No intuito de refletir sobre as concepções teóricas que abarcam essa questão, buscou-se aporte em estudos clássicos sobre os conceitos de região e redes; GRIGG (1973); MAGNANO (1995); GOMES (1995); HAESBAERT (1999), SANTOS (2003), CORRÊA (2003, 2011); CASTELLS (2006); SOUZA, et al.(2009). Neste âmbito, este artigo está estruturado em três seções: a primeira se refere ao marco teórico que fundamenta as discussões e análises apresentadas no escopo do texto; a segunda contextualiza o projeto de convivência com a seca, construído por meio da ASA e por fim, na terceira parte apresenta-se uma análise mais aprofundada das experiências do semiárido mineiro, apontandose os atores e experiências envolvidas nessas redes socioterritoriais de enfrentamento à seca.

\section{REGIÃO: A CONSTRUÇÃO DE UMA CATEGORIA CIENTÍFICA}

Com o passar do tempo, a categoria analítica região sofreu mudanças conceituais significativas, principalmente em relação a forma como é percebida. Este fato está fundamentalmente associado às transformações paradigmáticas, conceituais e metodológicas pela qual passou o conhecimento geográfico. Neste contexto, na perspectiva da Geografia Clássica, a região aparece ligada à ideia de espaço geográfico. Para Milton Santos (2003), em meados do século XIX, a região apareceu na

\begin{tabular}{llllll}
\hline Caminhos de Geografia & Uberlândia - MG & v. 19, n. 67 & Set/2018 & p. 374-388 & Página 375
\end{tabular}


geografia moderna, como espaço natural, enfatizando as diferenciações espaciais marcadas pelo determinismo ambiental.

Para Corrêa (2003), essa corrente atribuía demasiada importância às condições naturais, especialmente às climáticas, por determinarem o comportamento do homem, interferindo na sua capacidade de progredir. Assim, surge o termo região natural, a partir, principalmente, da análise da relação entre o comportamento humano e a natureza. Ainda para o mesmo autor, a noção de região, poderia ser entendida como um ecossistema onde seus elementos encontram-se integrados e são interagentes. Ou seja, o espaço deveria ser interpretado pela diferenciação "natural" da superfície terrestre. No Brasil, o conceito de região natural, foi cunhado por Delgado de Carvalho e por Fábio Guimarães, visando com o seu uso, uma divisão de caráter prático e duradouro, que possibilitasse a comparação de dados estatísticos ao longo do tempo. A partir destas proposições foram estabelecidas as grandes regiões naturais, até hoje vigentes no país (MAGNANO, 1995).

Sendo assim, a categoria região que estava, inicialmente, associada a um recorte e/ou delimitação espacial, foi sendo reduzida a classificações e a um instrument meramente metodológico. Posteriormente, com o advento da Geografia Crítica, a região passou a enfatizar a dimensão econômica, sendo esta compreendida como um produto da divisão territorial do trabalho. Tão logo, a partir do avanço do protagonismo dos movimentos sociais e dos regionalismos, passou também a ser compreendida como um processo oriundo de valores e pertencimento dos sujeitos a determinadas espacialidades, cunhando, assim, inclusive, outra terminologia geográfica: a identidade regional.

A inserção dos aspectos relativos à vivência humana incrementou, mais tarde, a caracterização da paisagem regional, pertencente aos preceitos da Geografia Possibilista. Segundo Gomes (1995, p.55) a expressão "possibilismo" foi definida em 1922 por Lucien Fébvre no intuito de delimitar uma explicação definitiva a influência dos elementos naturais na constituição de certos gêneros de vida, sendo, todavia, "a sociedade, seu nível de cultura, de educação, de civilização, que tem a responsabilidade de escolha, segundo uma fórmula que é bastante conhecida - 'o meio propõe, o home dispõe"'. Posto isso, os estudos regionais passaram a considerar as pequenas áreas levando em conta os aspectos físicos e a eles sobrepondo os humanos e econômicos. Admitia-se que o meio físico é o suporte que os seres humanos utilizam para sobreviver, construindo e produzindo o que necessitam. Para Corrêa (2003), a região nesse momento, dava ênfase à ação modeladora do homem sobre a natureza, criando paisagens e gêneros de vida próprios e peculiares a cada porção espacial.

A região passou a ser encarada como um constructo intelectual podendo variar em sua delimitação dentro das perspectivas quantitativas. Portanto, haveria certo grau de racionalismo na busca pela morfologia da paisagem que não se preocupava apenas com o único, o singular, mas também com a comparação dessas paisagens individuais, num sentido corológico pleno, isto é, da ordenação de paisagens culturais (HAESBAERT, 1999). Para o referido autor, a região deve ser compreendida a partir da multiplicidade e complexidade dos processos que marcam os seus arranjos espaciais na contemporaneidade. Não obstante, a regionalização pode variar, visto que a região pode ser vista como um espaço-momento sendo moldada a partir da articulação espacial em rede.

Os estudos regionais procuravam compreender as unidades componentes da diversidade da superfície terrestre. Em cada lugar, área ou região a combinação e a interação das diversas categorias de fenômenos refletiam-se na elaboração de uma paisagem distinta, que surgia de modo objetivo e concreto (SOUZA, et.al., 2009). Contudo, frente à supremacia do conceito de espaço, as noções de lugar e paisagem foram abandonadas e o conceito de região perdeu importância, reduzindo-se a um processo de classificação de unidades espaciais segundo procedimentos de agrupamento e divisão lógica com base em técnicas estatísticas (CORRÊA, 1995).

Gomes (1995) aponta que a região passou a ser analisada descritivamente, procurando ver a integração única dos fenômenos heterogêneos no espaço. Como fruto da influência neopositivista, a análise regional desta perspectiva estava isenta da historicidade, não sendo considerada uma entidade concreta. David Grigg (1973) advoga que a região é uma criação intelectual com propósitos específicos, pois cada pesquisador conduzirá os critérios selecionados para se realizar uma divisão regional. Portanto, a região era fundamentada por um caráter de classificação, agrupamento, subsidiada por técnicas estatísticas sofisticadas de laboratório, e por uma linguagem mais burocrática e rica, amparada pelas grandes teorias e em dados estatísticos, logo, afastada do trabalho de campo. Daí surge a possibilidade de classificar o espaço, ou seja, de regionalizar em regiões homogêneas, funcionais ou polarizadas, administrativas de forma sistemática. Constroem-se, assim, regiões cristalizadas no tempo e no espaço.

$\begin{array}{llllll}\text { Caminhos de Geografia } & \text { Uberlândia - MG } & \text { v. 19, n. } 67 & \text { Set/2018 } & \text { p. 374-388 } & \text { Página } 376\end{array}$


A partir da década de 1970, Corrêa (2003) destaca que as reflexões a respeito do conceito de região foram marcadas pela articulação dos meios de produção, das ligações entre acumulação capitalista e classes sociais, por meio das relações entre Estado e sociedade local. Ou seja, buscava-se a incorporação dos processos históricos e culturais, a fim de alcançar a subjetividade, a heterogeneidade, a descontinuidade ou a diferença nas escalas de análise dos processos sociais. Lencione (1999) coaduna com Corrêa (2003) ao enfatizar a escala regional como intermediadora na análise entre o singular e o universal, sendo capaz de divulgar a espacialidade particular dos processos sociais globais. Nesse sentido, permite-se ao regional se reabitar frente ao global como particularidade da globalização. A autora ainda salienta que a região é uma espacialidade diferencial de processos sociais e naturais, não é um produto de processos particulares regidos por leis particulares e sim leis gerais que encontram suas particularidades regionais.

Nessa perspectiva, a análise regional media a relação entre a escala local e a escala global e tornamse mais evidentes aspectos da realidade que, possivelmente, seriam imperceptíveis se fossem analisados a partir do global. Corrêa (2003), ainda afirma que a ressurreição dessa região se dá principalmente, pelo viés da dimensão econômica, e também pelo viés dos movimentos sociais, de forma que, a transformação das regiões não traria a homogeneização do mundo, mas sim, um processo de valorização das particularidades de cada lugar, em relação às especificidades herdadas do seu passado e aos processos advindos da globalização (HAESBAERT, 1999).

A escolha do conceito de região como instrumento analítico para subsidiar as discussões tecidas nesta investigação, ocorreu em função do quanto este conceito consegue reforçar as dinâmicas locais presentes no semi-árido mineiro. Portanto, o semi-árido deixa de assumir um viés descritivo do espaço, como outrora era reconhecido e, ganha particularidades, ao se considerar as diferenciações regionais ali presentes. Sendo assim, a região pode ser aqui concebida não como um simples recorte empírico ao se tratar do semi-árido, nem como uma mera ferramenta de análise. A região é aqui compreendida, como um recorte, um método e uma ferramenta politica capaz de indicar as representações existentes no semi-árido mineiro.

Vinculado a esta nova concepção conceitual, o semiárido passa a ser compreendido como um recorte regional que possui uma questão comum - as condições ambientais vinculadas ao clima, às quais são atribuídas diversas formas de interação e articulação que distinguem as relações sociais e aspectos culturais dos sujeitos que vivenciam esta porção espacial. No intuito de reconhecer essas relações geral-particular e singular-universal que buscou-se compreender como essa construção conceitual se concebe no âmbito das ações e mediações da Articulação do Semiárido (ASA), entidade que por meio dos diversos discursos da seca, busca revalorizar o singular procurando evidenciar a capacidade de grupos humanos de recriar espaços múltiplos de sociabilidade. Nessa perspectiva, para se alcançar o objetivo proposto de identificar as concepções regionais presentes nos discursos vinculados à seca, a compreensão do conceito de região nos auxilia a clarificar as múltiplas manifestações e representações regionais presentes no semiárido mineiro, evidenciando, a partir de suas distintas epistemologias, os verdadeiros significados que se encontram atrelados a essas regionalizações.

\section{ARTICULAÇÃO DO SEMIÁRIDO (ASA) - DANDO VOZ AO DISCURSO DA CONVIVÊNCIA}

$\mathrm{Na}$ década de 1950, as Ligas Camponesas já buscavam, por meio dos movimentos, incursões populares e políticas públicas, dar voz aos sujeitos e populações camponesas locais. Esse movimento foi sendo fortalecido, posteriormente, com a configuração das Comunidades Eclesiásticas de Base, da Igreja Católica, no período de 1960-1980 e pelos Sindicatos dos Trabalhadores Rurais (STR), em 1970. Com o processo de democratização na década de 1980, os movimentos populares tomaram força ainda maior, lutando por seus direitos previstos pela Constituição de 1988, o que lhes proporcionou, inclusive, uma maior autonomia em relação aos partidos políticos, movimentos religiosos e sociais.

No caso do semiárido, frente à necessidade de desenvolvimento econômico requerido no período dos governos democráticos, várias políticas de combate à seca foram estruturadas, sem, no entanto, dialogarem com as necessidades e reivindicações reais desses sujeitos que lidam com a seca diariamente. O estigma da pobreza e da seca foi implantado e oficializado a partir da consolidação do processo de Regionalização do Semiárido Brasileiro, que abrange atualmente 969.589,4 km² compreende 1.133 municípios de nove Estados do Brasil: Alagoas, Bahia, Ceará, Minas Gerais, Paraíba, Pernambuco, Piauí, Rio Grande do Norte e Sergipe. A seca, apesar de ser uma realidade

$\begin{array}{llllll}\text { Caminhos de Geografia } & \text { Uberlândia - MG } & \text { v. 19, n. } 67 & \text { Set/2018 } & \text { p. 374-388 } & \text { Página } 377\end{array}$


natural daquele meio físico, foi declarada como um problema - um flagelo social a ser combatido pelas políticas governamentais. Instaurou-se uma ação estatal autoritária, baseada em medidas emergenciais assistencialistas (caminhões pipa, construção de açudes, cisternas e etc.) e na apropriação privada dos investimentos públicos pelas oligarquias.

$\mathrm{Na}$ década de 1980, tais deficiências nas políticas com o semiárido já haviam sido sinalizadas pela EMBRAPA (Empresa Brasileira de Pesquisa Agropecuária) no documento Convivência do Homem com a Seca, indicando, inclusive, como eixo central para a questão, a capacitação e armazenamento de água. Na década seguinte, quando a sociedade civil e os movimentos populares passaram a se inserir mais ativamente nessa discussão, outras questões também foram indexadas ao debate, tais como; o conhecimento e respeito às condições ambientais locais do semiárido; a convivência e experiência do povo compartilhado com as instâncias governamentais e o desenvolvimento sustentável para a segurança alimentar e hídrica (ASSIS, 2012). Já se destacava, como bem ressaltam Freire e Falcão (2013, p.36), uma construção regional pautada a partir de uma "identidade comum", de "um projeto coletivo que se funda no princípio da convivência com o semiárido e se materializa em processos locais de experimentação agroecológica articulados em redes de agricultoras e agricultores experimentadores".

É nesse ambiente, apoiado por influências como da Superintendência do Desenvolvimento do Nordeste (SUDENE); Fórum da Seca (1991); Fórum Campo no Rio Grande do Sul (1994) e da própria Articulação do Semiárido, que, no território paraibano, já se configurava desde 1993, o projeto ASA-Brasil, o qual se consolidou, efetivamente, durante a $3^{\text {a }}$ Conferência das Partes da Convenção de combate à Desertificação e à Seca (COP-3) realizada em Recife no ano de 1999. Paralelamente a este evento, as entidades que já se organizavam em torno da ASA, mobilizaram se no "Fórum Paralelo da Sociedade Civil" com o intuito de reivindicar maior visibilidade às questões da convivência com o semiárido, se consolidando como ASA-Brasil por meio da Declaração do semiárido, a partir da qual é lançada a proposta do Programa Um Milhão de Cisternas (P1MC) (ASA, s/d, s/p.).

$\mathrm{Na}$ Declaração do semiárido, a ASA explicita as instituições e organizações que se adequariam aos princípios e concepções estruturantes da rede, tais como: entidades ambientalistas; associações comunitárias; cooperativas; movimentos de mulheres; universidades e o próprio Sindicato dos Trabalhadores Rurais, que segundo Malvezzi (2007, p.61):

\section{[...] logo se espalharam pelo Brasil, com força no Semiárido, impulsionados por integrantes da Igreja Católica. (...) com propostas inovadoras no campo das tecnologias sociais e na criação de uma cultura de emergência com o ambiente local. Essas iniciativas, que muitas vezes foram pontuais, tornaram-se cada vez mais orgânicas, com proposta políticas, que confrontam o modelo das velhas oligarquias, baseadas na indústria da seca, ou das novas oligarquias, baseadas no agronegócio e no hidronegócio.}

Ressalta-se ainda neste documento o papel estruturante dos Sindicatos dos Trabalhadores Rurais, principalmente, no âmbito de sua atuação como articulador local, o qual, inserido no viés das políticas públicas, se consolidou como apoiador e veiculador de grande parte das experiências de convivência com o semiárido, através de mobilizações, cursos, financiamentos e etc.

Outro fator importante evidenciado na declaração é o papel da água como um elemento indispensável para a convivência com o semiárido, comprovado por especialistas de várias nacionalidades e como ressaltou a ASA (1999) ao afirmar que a captação da água de chuva no semiárido seria uma fonte hídrica suficiente para as necessidades produtivas e sociais da região. E é nessa perspectiva que as cisternas se tornaram um elemento chave na política de convivência do semiárido: água para beber e para produzir.

Segundo Assis (2012, p. 184) para que programas como a ASA e os movimentos sociais se consolidassem de forma efetiva no cenário nacional seria preciso que seus posicionamentos e ações transformassem "questões" em "problemas". Ou seja, era preciso que "situações sociais para as quais as pessoas dirigem atenção - questão - despertem no poder público uma ação quando se transforma em um problema. Para tal, foi necessário chamar a atenção governamental a partir de crises ou símbolos representativos (pior crise hídrica do Nordeste em 1998-1999); apoiar-se em indicadores sociais e quantitativos que apontem a existência de uma questão (mais de 3 milhões de pessoas necessitando de frentes emergenciais em decorrência da seca) e

$\begin{array}{llllll}\text { Caminhos de Geografia } & \text { Uberlândia - MG } & \text { v. 19, n. } 67 & \text { Set/2018 } & \text { p. 374-388 } & \text { Página } 378\end{array}$


comprovar a ineficiência de possíveis programas que estejam sendo desenvolvidos (pessoas sem água para beber em locais onde foram construídos açudes), mas que não possuem uma solução efetiva para a questão. Assim, segundo o autor:

\begin{abstract}
A ASA desempenha esse papel de construir um problema quando chama atenção para a necessidade de convivência com o semiárido e capitaliza o interesse governamental na elaboração de soluções alternativas [...] no caso do $\mathrm{P} 1 \mathrm{MC}$, as organizações da ASA tratam de capitalizar a percepção quanto à validade do problema, e também quanto à validade da tecnologia, mostrando [...] a construção de cisternas com viabilidade técnica, baixo custo, grande aceitação e resultados positivos em relação ao fornecimento de água para beber (ASSIS, 2012, p.184-185).
\end{abstract}

Tendo em vista o poder articulador da ASA em 2000, após a consolidação da Declaração do Semiárido (1999), foi estabelecido o primeiro convênio do Programa Um Milhão de Cisternas (P1MC), com o poder público, no âmbito do Ministério do Meio Ambiente, para a construção de 500 cisternas. No ano seguinte, foi instituído um convênio com a recém-criada Agência Nacional de Águas (ANA), chamado de P1MC-T, pois além da construção de 12.400 cisternas, sendo 1000 de contrapartida da ASA, o convênio prestaria ainda cursos de capacitação, comunicação e mobilização social nas áreas atendidas.

Um dos avanços significativos do projeto foi a criação da Associação Projeto Um Milhão de Cisternas - AP1MC, ao qual ficou responsável por assumir os convênios com as iniciativas estatais. A partir de então, em 2003, foi assinado o 1ำ Termo de Parceria com o Ministério do Desenvolvimento Social e Combate à Fome (MDS) para construção de 22.400 cisternas. Nesse sentido, o P1MC deixou de ser uma ação isolada, apoiada pela ANA, e passou a figurar como um programa de maior destaque no governo federal (ASSIS, 2012, p.187). Segundo Carvalho et al. (2017), além da importância de amenizar as dificuldades oriundas da seca, uma vez que as cisternas, sozinhas, ainda não viabilizam a convivência em todo o período da estiagem, o programa P1MC viabilizou também uma transformação social muito significativa no modo de vida dessas pessoas, cujo tempo destinado à busca e transporte da água coletada nos açudes, agora vem sendo investido, inclusive, em outras práticas criativas de coleta e armazenamento de água da chuva.

Nesse novo contexto, vários outros programas foram criados no intuito de contemplar o P1MC e mais recentemente o $\mathrm{P} 1+2$ (o 1 significa terra para produção e o 2 corresponde a dois tipos de água: a potável para consumo humano e água para produção de alimentos). Atualmente, o grande financiador é o Governo Federal, mas existem também recursos oriundos do Governo do Estado de Minas Gerais - Fundo de Recuperação das Bacias Hidrográficas (Fhidro) e de diversas ONGs como: Coordenadoria Ecumênica de Serviço (CESE); Cáritas, Sindicato dos Metalúrgicos do ABC Paulista; Fundação Konrad Adenaver, Catholic Relief Services e Misereor, dentre outros.

O papel transformador dessa entidade pode ser percebido no biênio de 2012-2013, quando os institutos meteorológicos indicaram o período de seca mais severo do semiárido nos últimos 50 anos, o qual, contudo, não foi veiculado pelas mass mídias como um círculo vicioso da pobreza e da miséria. Mas, evidenciaram-se, as "dinâmicas descentralizadoras de inovação social ativadas pela criatividade popular" dos agricultores e agricultoras do semiárido brasileiro (FREIRE; FALCÃO, 2013, p.36). Ainda segundo estes autores, tal conjuntura se deve também a uma combinação de importantes fatores socioeconômicos. O primeiro deles é a Programa Bolsa Família, que por meio da transferência de renda, viabilizou condições básicas para as necessidades vitais de muitas famílias, que puderam assim, "liberar suas energias criativas para investir no desenvolvimento de variadas estratégias de reprodução econômica e sociocultural" (FREIRE; FALCÃO, 2013, p.36).

Para a ASA e suas entidades articuladas, as secas são fenômenos naturais periódicos que não podemos combater, mas com os quais podemos conviver (ASA, 1999, p.2). E conviver não é adaptar-se, mas sim viver junto com a seca, aprender a lidar com suas limitações e possibilidades, frente à diversidade natural e social que configuram o semiárido. Neste interim, a convivência corresponde também à troca de experiências, que para além das oficinas e fóruns locais, passa pela divulgação e documentação por meio do boletim informativo "O Candeeiro" um banco de experiências de agricultores e agricultoras que convivem com o semiárido. 


\section{O CANDEEIRO - A REDE DE EXPERIÊNCIAS DE CONVIVÊNCIA COM O SEMIÁRIDO MINEIRO}

Os processos de regionalização, ou seja, de demarcação e reconhecimento de áreas, que apesar de suas singularidades, possuem elos comuns de identificação, sempre se consolidam em quadros territoriais amplos, grandes porções de terras, cuja conexão entre suas populações, muitas vezes distantes umas das outras, é dificultada ainda pela própria condição precária de infraestruturas básicas como estradas e linhas de comunicação. Todavia, mesmo em tempos remotos, a comunicação entre esses lugares sempre se fez presente por meio das rádios, feiras, carros de som, jornais e panfletos locais, dentre outros. E é nessa perspectiva, da identificação dos sujeitos com suas regionalidades e da força das trocas de experiências e viências entre eles, que o conceito de região se consolida enquanto uma força identitária consubstancial. Assim, a troca de experiências sempre existiu, entretanto, em intensidades de tempo e espaço muito distintas das atuais, cujos impactos e conflitos dos grandes capitais, demandam ainda, de certa forma, uma comunicação ainda mais intensa e rápida pelas redes sociais ou por reportagens como as veiculadas nos boletins do Candeeiro.

A importância dessa rede de experiências do Candeeiro no Estado de Minas Gerais, se destaca não apenas como uma troca de experiências e relatos de convivência, mas ainda como um significativo articulador político e social de princípios que fundamentam a constituição dessa identidade comum, revelados, inclusive, na própria coerência das reportagens com os pontos principais apresentados na Declaração do Semiárido Brasileiro, tais como: a valorização das experiências locais e das diversidades regionais; a construção de um programa de convivência com o semiárido pautado nas concepções da sustentabilidade; fortalecimento da sociedade civil com a inserção de jovens e mulheres nos programas de desenvolvimento, dentre outros.

No período de 2009 a 2017 foram levantadas no Boletim Candeeiro (que engloba todo o semiárido brasileiro) 113 experiências relacionadas ao semiárido mineiro. Destas, observou-se que, para além dos 85 municípios que compõem esse recorte regional, segundo a Articulação do Semiárido, foram noticiadas ainda experiências de outros cinco municípios localizados próximos ou no entorno dessas realidades e que configuram significativos polos regionais, são eles: Chapada Gaúcha, São Francisco, Montes Claros, Turmalina e Veredinha - como pode ser observado na Figura 1. Tal resultado é um indicativo forte do protagonismo dessas comunidades, que apesar de não estarem inseridas "oficialmente" no recorte em questão, se identificam como tal e reconhecem a importância de compartilhar suas experiências locais no âmbito dessa rede. A análise cartográfica e espacial de tais experiências apresentada na figura abaixo nos revela ainda que, grande parte dos municípios pertencentes a este recorte regional tiveram suas experiências veiculadas pelos boletins, destacando-se em números, principalmente, os municípios próximos à Cáritas de Januária - importante articuladora do norte de Minas.

As primeiras experiências mineiras encontradas no boletim, no ano de 2009, retratam principalmente a luta do povo Xacriabá para a demarcação de seu território tradicional, educação indígena, implantação de um viveiro, recuperação das nascentes e resgate e preservação da medicina indígena. Experiências que se apoiam na primeira premissa de convivência com o semiárido: "conservação, uso sustentável e recomposição ambiental dos recursos naturais do semiárido" (ASA, 1999, p.2).

Os povos tradicionais de Minas Gerais, como vazanteiros, indígenas, geraizeiros e quilombolas aparecem em dezesseis boletins relatando experiências em manejos tradicionais da terra, produção diversificada e alternada de acordo com as condições climáticas. Como na demanda e lutas pela demarcação do seu território tradicional que se encontra, de alguma forma, ameaçado por grandes empreendimentos, tais como empresas de eucalipto, ou pela implementação de unidades de conservação que restringem o acesso e uso sustentável de áreas, que vem sendo, inclusive, preservadas por essas populações. Nas experiências compartilhadas pelas comunidades quilombolas do semiárido, o aspecto que mais se ressalta é a importância das Associações Comunitárias na construção do protagonismo político desses grupos, o qual, segundo Miné e Rodrigues (2012) vem se consolidando desde 1980, com a atuação das Comunidades Eclesiásticas de Base (CEBs), com os Centros de Referência da Cultura Negra e com o fortalecimento da identidade quilombola que, por meio dessas associações, tem reivindicado programas, projetos de desenvolvimento rural, valorização e resgate da cultura e da identidade quilombola, além da própria titulação de suas terras. 
Figura 1: Mapa Distribuição Espacial das Experiências de Convivência do Semiárido Mineiro Boletim Candeeiro $2009-2017$

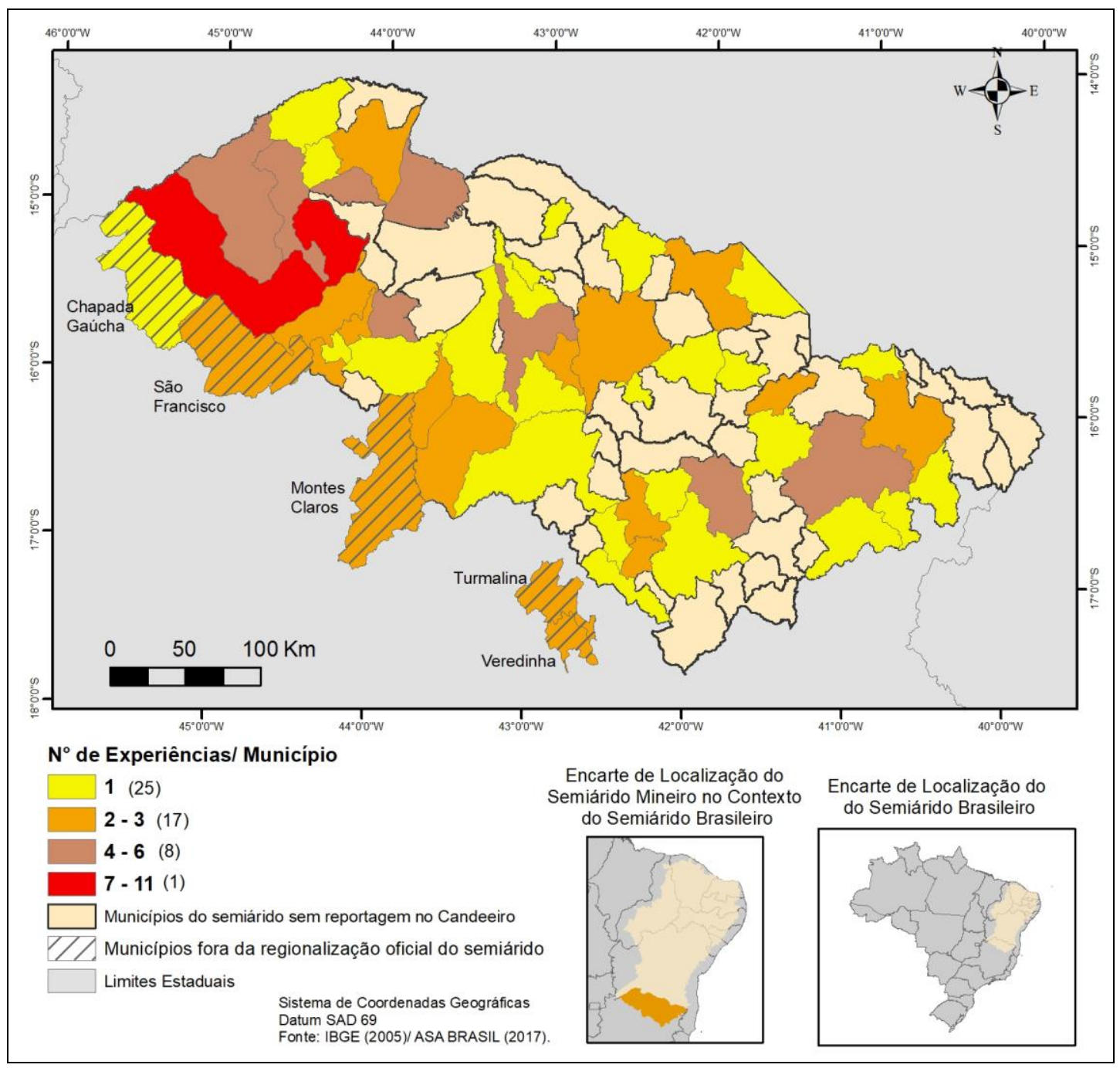

FONTE: Elaborado pelos autores, 2017.

As vivências dos Assentamentos do Semiárido Mineiro - que segundo dados do INCRA (2017), giram em torno de 86 territórios, correspondem à $34 \%$ dos assentamentos de Minas Gerais somando uma população de 4 mil famílias, também são relatadas nos candeeiros. Os 13 assentamentos analisados nos boletins, localizados principalmente no município de Jequitinhonha, trazem diversas experiências relacionadas primordialmente aos desafios de se manter na terra conquistada, uma vez que, segundo eles, os incentivos governamentais demoram a chegar após a conquista do território. Nesse sentido, os grupos começam a se mobilizar por meio das associações e cooperativas que passam a captar projetos junto a outras entidades como Cáritas, Asa, Sindicato dos Trabalhadores Rurais, Centro de Agricultura Alternativa (CAA) dentre outras entidades e ONGs que podem auxiliar na construção de projetos de manejo sustentável no semiárido. Essa resiliência da luta dos assentados pode ser exemplificada ainda nas falas a seguir:

Através da luta pela terra e da implementação do Assentamento, a associação passou a buscar parceria para resolver a questão da falta de água e de manejos sustentáveis e agroecológicos para conviver com o semiárido! (Assentado de Varzelândia - O CANDEEIRO, 2011, p.2).

[...] disseram que eu ia morrer de fome aqui. Eu disse que nunca vi ninguém morrer de fome em cima da terra. Sentei o pau trabalhando, passado 3 anos já tinha uma boa produção de mandioca, batata doce, milho e capim. Primeiro eu plantei o milho 
e mandioca para conseguir alimentar os animais, gado, cavalo, galinha. Agora já tem de tudo: feijão, melancia, abóbora, manga, caju, pinha, laranja, mamão, seriguela, acerola, abacate (Assentado de Matias Cardoso, O CANDEEIRO, 2013, p.1).

Outro fator que chama atenção nessas experiências é a importância que é dada às hortas nos quintais. Apesar das iniciativas de projetos de hortas comunitárias, em algumas situações serem impostas, inclusive pelas entidades estatais, esses espaços produtivos exercem sua função de segurança alimentar no espaço dos quintais, nas proximidades das casas, onde os agricultores podem resgatar seus modos tradicionais de plantio e cultivo de hortaliças e verduras, além das práticas de controle natural de pragas e adubação orgânica. Tais experiências, em sua maioria, dialogam constantemente com uma rede agroecológica composta por entidades como o Centro de Agricultura Alternativa (CAA) de Montes Claros; Instituições Públicas de Ensino Superior; Rede de Intercâmbio de Sementes (RIS) e os próprios Guardiões das Sementes Crioulas, que através das suas casas de sementes comunitárias e regionais, configuram uma rede de trocas e manutenção da biodiversidade do cerrado, como é expresso na fala a seguir. Vale ressaltar ainda que, no ano de 2017, o governo do Estado Minas Gerais lançou um novo programa de Sementes da Gente, no qual apoiará diversos projetos de construção de casas comunitárias de sementes.

\begin{abstract}
"As sementes não são importantes somente para as famílias que cultivam e mantém esta prática há décadas e séculos. São importantes para toda a comunidade, porque não se desvincula as famílias das comunidades. Tudo isso é interessante porque se a família possui as sementes crioulas, ela tem autonomia para garantir a segurança alimentar dos agricultores e agricultoras, Povos e Comunidades Tradicionais", Explica Lô - agricultora familiar do município de Riacho dos Machados (Assentados e Geraizeiros - O CANDEEIRO, 2015, p.3).
\end{abstract}

O relato da agricultora demonstra que, para além da segurança alimentar, a rede de sementes é fundamental para a união, preservação cultural e manutenção dos jovens nas comunidades, pois com a produção de excedentes, estes poderão vender seus produtos nas feiras, alcançando uma renda para adquirir outros bens de consumo de seu desejo. Nesse sentido, as feiras também se configuram como pontos importantes dessa rede, onde além da venda dos produtos, se consolida mais um espaço de trocas de experiências da rede socioterritorial do semiárido.

A feira não é só um espaço de comercialização, mas também de mobilização social. É onde as pessoas se encontram, conversam, se mobilizam. Ali ocorrem também apresentações musicais, rodas de capoeira e outras manifestações culturais. "A feira é um lugar de vender produtos saudáveis" Marta Leci - agricultora familiar do município de São Francisco (O CANDEEIRO, 2012, p.2).

Tais experiências revelam, mais uma vez, a concretização de um dos pilares do programa incluir jovens e mulheres no processo de desenvolvimento (ASA, 1999, p. 3). O papel desses dois atores sociais se desdobra ainda em outro ponto importante que é o fortalecimento da sociedade civil por meio do reforço de organização dos atores sociais e da geração e difusão de informações e conhecimentos no campo. É nesse sentido, que Nascimento (2016) pontua a importância da comunicação popular para a mobilização social, veiculada e instituída pela formação dessas redes de trocas estabelecidas por meio dos Candeeiros, ou, ainda, das feiras agroecológicas, da comercialização solidária e dessa construção coletiva do conhecimento.

Um desses desdobramentos foi a experiência da Rádio comunitária A Voz do Agricultor, dirigida principalmente por jovens, divulgada em 2012, cujo objetivo era incentivar a organização comunitária e despertar o interesse das famílias para a importância da comunicação popular. Apesar de alguns percalços impostos pela "dominação política hereditária da região", o programa conseguiu sobreviver, principalmente nos municípios de Ibiracatu e Varzelândia, onde é apresentado o programa "Riquezas da Caatinga", produzido pela ASA Brasil, para que os agricultores conheçam e se identifiquem mais com a sua região, que é semiárida (CANDEEIRO, 2012a, p.1).

Outro ponto importante a se ressaltar é o papel das mulheres não apenas como articuladoras de um saber local, como de mobilizadoras sociais para criação de associações, implementação de feiras e representação política das comunidades. No intuito de se viabilizar enquanto uma rede de articulações do semiárido, a ASA-Brasil busca transformar um elemento que é zonal, uma região, em algo mais fluido, não apenas uma região em sua dimensão ampla do semiárido, mas concebendo inclusive as singularidades dos diferentes territórios que compõem este recorte regional e que se comportam, em certa medida como redes socioterritoriais, como ressalta Coelho Neto (2014) a seguir:

$\begin{array}{llllll}\text { Caminhos de Geografia } & \text { Uberlândia - MG } & \text { v. 19, n. 67 } & \text { Set/2018 } & \text { p. 374-388 } & \text { Página } 382\end{array}$


Queremos nos referir a uma gama variada de modalidades organizativas da sociedade civil que se apropriam da noção de redes como estratégias de comunicação e empoderamento da sociedade civil, propiciando a articulação política desses atores sociais na contemporaneidade, sejam como atores de resistência ou como propositores de políticas públicas. Nesse sentido, as redes assumem duas perspectivas distintas como forma organizacional ou como estratégia de ação e de inter-relação com outros poderes instituídos, em face das possibilidades de estabelecimento de relações mais horizontalizadas, descentralizadas e democráticas (COELHO NETO, 2014, p.139).

Nesse sentido, a rede socioterritorial do semiárido mineiro se desvela principalmente a partir das estratégias de ação e inter-relação constituídas primordialmente no seio da família. É a mulher, a sabedoria do agricultor familiar e das comunidades tradicionais, o espírito inovador dos jovens que sobre a concepção da coletividade e da alteridade que inspiram e fortalecem a convivência com o semiárido. As ações governamentais, ONGs, entidades religiosas e a própria articulação funcionam, nesse sentido, como mediadoras e viabilizadoras de projetos que fortalecem a articulação política e estratégias de resistência desses sujeitos, que são, por sua vez, protagonistas de sua própria história e da sua mobilização enquanto uma entidade regional.

\section{A REDE SOCIOTERRITORIAL DO SEMIÁRIDO MINEIRO - À LUZ DO CANDEEIRO}

A fim de compreender como a ASA e o boletim "O Candeeiro" se consolidam como estruturas fundamentais na articulação da rede socioterritorial do semiárido, é preciso refletir como a sociedade vem se organizando por meio da construção de redes, sejam elas sociais, informacionais, econômicas ou sociopolíticas. Tais interações, neste contexto, propiciam ainda uma intensa conexão e troca de saberes e informações entre as mais distintas e longínquas realidades. Todavia, muitas dessas interações são anteriores aos avanços da tecnologia, refletindo, como postula Castells (2006), em diálogos oriundos do domínio privado, das feiras locais e dos sistemas de troca intracomunitários. Hoje, esses limites são ultrapass ados não apenas em decorrência da autonomia ou das novas concepções de mundo dos sujeitos envolvidos, mas pela própria convicção de que vivemos em uma Sociedade em Rede. Desse modo, as redes, enquanto formas de organização social, são cada vez mais flexíveis e adaptáveis, seguindo, de modo muito eficiente, o caminho evolutivo dos esquemas sociais humanos, a partir da explosão de redes horizontais articulando o local ao global.

Ainda para o mesmo autor, a sociedade em rede não é uma situação futura, mas uma realidade vivida pela própria sociedade atual organizada em diferentes graus. Corrêa (2011) corrobora em certa medida com Manuel Castells (2006), ao afirmar que a espacialidade humana é parte fundamental na abordagem das redes, sejam elas sociais ou geográficas. Sobre a dimensão de análise das redes 0 autor sugere três dimensões básicas: a temporal, a organizacional e a espacial. A dimensão temporal estaria relacionada a duração, velocidade e frequência dos fluxos. Já a organizacional sugere que se considerem os agentes sociais, a origem, a natureza dos fluxos, a função, a finalidade, a existência, a construção, a formalização e a organicidade. E por fim, a dimensão espacial que envolveria as diferentes escalas e conexões. Desse modo, cada rede geográfica se consolidaria predominantemente a partir de um desses aspectos apresentados, o que não significa que eles sejam excludentes em si, e com a mesma intensidade, mas sim, de complexas relações entre estrutura, processo e função.

Para este autor, uma rede se torna geográfica quando, em sua análise, o espaço se faz presente, tornando-as com fluxos intensos, complexos e de poder. A rede geográfica a partir de então passa a ser percebida em diversas escalas, abordagens e recortes temporais, podem ser relacionadas ao contexto cultural, às temporalidades históricas, ao caráter funcional, às redes comerciais e financeiras, assim como às redes geográficas de expressão nacional e/ou global. Neste contexto, as transformações de redes ocorrem em virtude de novos processos que podem gerar novas interações e funções de maior ou menor grau afetando sua estabilidade e transformando-as de acordo com os interesses dos sujeitos envolvidos, ao longo do tempo e do espaço. Dessa forma, ao analisar o espaço sisaleiro da Bahia, Agripino Souza Coelho Neto (2013, p.387) alcunha o conceito de redes socioterritoriais, compreendendo-as como:

[...] determinadas modalidades de ações coletivas, cujos processos de formação e funcionamento se ancoram na territorialidade que, por sua vez, ocupa uma posição estratégica fundamental nas práticas sociais que elas empreendem. Em nosso caso empírico, trata-se de uma modalidade de ação coletiva que equivale

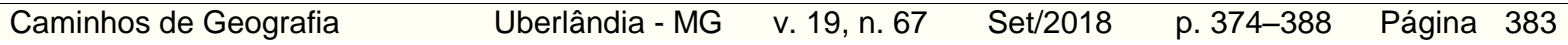


à constituição de organizações sociais de trabalhadores rurais (expressa no sindicalismo, associativismo, cooperativismo), mobilizando a territorialidade como estratégia socioespacial de organização, operação e afirmação.

Nesse direcionamento, a Articulação do Semiárido (ASA) é também compreendida enquanto uma rede socioterritorial, visto que, é uma iniciativa de mobilização social entre diversas entidades, que por meio de ações coletivas visam construir uma nova forma de lidar com as condições ambientais da seca, não a combatendo, como incitavam os discursos anteriores, mas buscando formas e alternativas de conviver com essa realidade comum. E é justamente essa capacidade da sociedade de se mobilizar que revela o potencial interno das redes socioterritoriais, permitindo uma experimentação do que desmistifica o discurso de homogeneidade regional, uma vez que tais comunidades se destacam por suas singularidades e distinções de buscar essas maneiras do conviver com o semiárido, exaltando as dinâmicas diversas das realidades locais que compõem tal recorte geográfico.

Como bem ressalta Nascimento (2016, p.2), o boletim candeeiro além de dar voz e visibilidade aos agricultores, comunidades e diversos grupos do semiárido, se configura ainda como uma "ferramenta de comunicação institucional no fortalecimento das organizações que compõem o coletivo da ASA". Circunstancialmente, para se compreender essa configuração da rede socioterritorial que se consolida nesse recorte regional, buscou-se identificar os diversos sujeitos atuantes nesse espaço, a partir das publicações do Candeeiro (Figura 2).

Foi possível identificar uma plêiade de entidades atuantes no semiárido mineiro, a Cáritas Brasileira - organismo da Conferência Nacional dos Bispos do Brasil (CNBB) (Regional Minas Gerais; Diocesana de Almenara, Diocesana de Janaúba e Diocesana de Januária); outras entidades religiosas (Comissão Pastoral da Terra, Instituto Marista Solidariedade e Coordenadoria Ecumênica de Serviço); entidades privadas (Banco do Brasil e Petrobras apoiadores do Programa Cisternas); entidades internacionais (ActionAid e WWF); ONGs/ OSCIP (Grupo Agroextrativista do Cerrado e Agência de Desenvolvimento Sustentável do Vale do Rio Urucuia - Adisvru); entidades governamentais (Companhia de Saneamento de Minas Gerais COPASA; Instituto de Desenvolvimento do Norte e Nordeste de Minas Gerais - IDENE; Serviço Nacional de Aprendizagem Rural - SENAR; Instituto Mineiro de Gestão das Águas - IGAM; Empresa de Assistência Técnica e Extensão Rural do Estado de Minas Gerais - EMATER; Instituto Brasileiro do Meio Ambiente e dos Recursos Naturais Renováveis - IBAMA; Instituto Estadual de Florestas - IEF; Assistência Técnica e Extensão Rural - ATER; Centro de Referência de Assistência Social - CRAS e Prefeituras); centros de ensino e pesquisa (Universidade Federal de Minas Gerais, Universidade Federal dos Vales do Jequitinhonha e Mucuri, Institutos Federais de Educação, Ciência e Tecnologia (IFET's) e o centro de documentação "Instituto Sociedade, População e Natureza" - ISPN); Sindicato dos Trabalhadores Rurais (STR); Centro de Agricultura Alternativa no Norte de Minas (CAA); associações comunitárias locais e a própria ASA. Dentre eles, os mais mencionados no Candeeiro, foram as associações comunitárias locais (37 menções); a Cáritas (33); a ASA (26); o STR (16); o CAA (13); as demais entidades religiosas (12) e por fim, as Universidades e Centros de Ensino e Pesquisa (10) em mesma representatividade que diversas entidades governamentais (10). Na Figura 2, a seguir, pode-se observar o escopo de atuação dessas entidades assinalando uma ampla cobertura e capacidade organizativa no semiárido de Minas Gerais.

Tais resultados revelam a importância cada vez maior do protagonismo dessas comunidades, muitas vezes desvinculado, inclusive, de programas e entidades, fato reforçado também pelo volume expressivo de boletins que relatam experiências individuais de famílias ou comunidades do semiárido. Além disso, pode-se destacar a intensa relação histórica desse recorte regional com as entidades religiosas, como a Cáritas, uma das mais atuantes não apenas no semiárido, mas em diversos outros contextos mundiais nos quais se encontram em situações de vulnerabilidade social. Outro aspecto importante a ser assinalado é a presença das Universidades, centros de ensino e pesquisa, bem como, as entidades governamentais que foram descritas com a mesma frequência, não apenas em números, como também na forma de atuação, viabilizando projetos de pesquisa ou diagnósticos regionais, que, em sua maioria, trazem poucos retornos efetivos para as comunidades. 
Figura 2: Mapa de Distribuição Espacial da atuação de entidades vinculadas às Experiências de Convivência do Semiárido Mineiro, segundo os boletins do "Candeeiro" entre 2009 - 2017

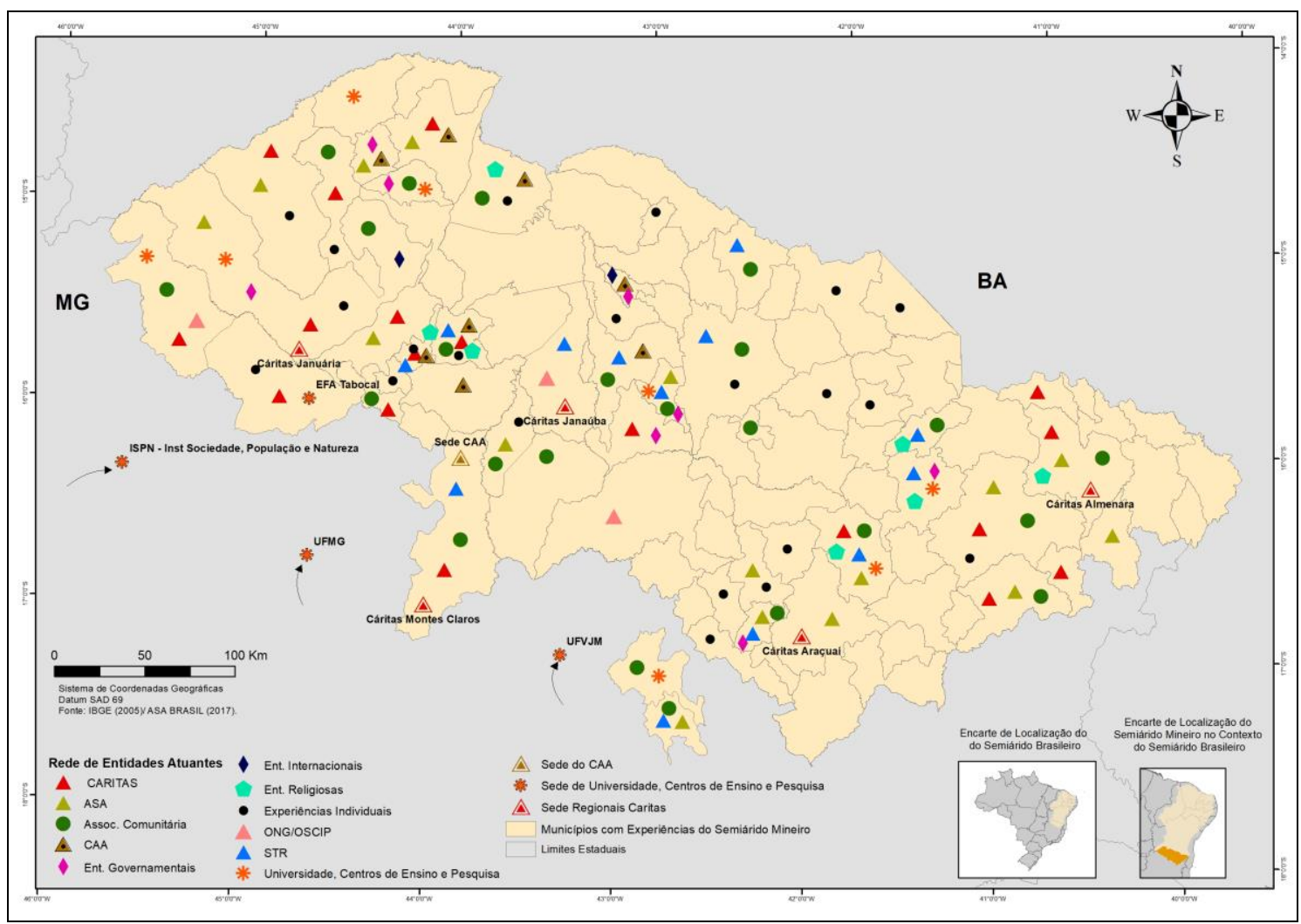

Fonte: Elaborado pelos autores.

Muitas dessas entidades configuram-se como verdadeiros nós dessa rede de articulação do semiárido, atuando como parceiros e mobilizadores desse protagonismo emergente das comunidades rurais. Um importante nó dessa rede, além da ASA, como evidenciado na Figura 1, é o Centro de Agricultura Alternativa do Norte de Minas (CAA), cujas ações são primordialmente voltadas à valorização dos saberes locais, aos manejos e técnicas agroecológicos e a recuperação, conservação e aproveitamento dos recursos naturais, atuando também por meio das redes de articulação e da formação social e política de seus parceiros. Essa organização de agricultores familiares e povos e comunidades tradicionais vem atuando, desde 1985, no intuito de fortalecer uma rede sócio-técnica, na qual os saberes e experiências de camponeses, dos técnicos agrícolas, de especialistas, universidades e entidades parceiras, são articulados no sentido de viabilizar esforços e soluções efetivas para os grandes dilemas ambientais, sociais, econômicos e políticos dos Cerrados e Semiáridos brasileiros (CAA, 2017).

Em vias de conclusão, essas entidades distintas, representam, na perspectiva regional e das redes socioterritoriais, eixos de conexão (ou nós) de uma articulação de vivências que expressam o protagonismo político e social das comunidades do semiárido. São essas entidades que alimentam a rede invisível de experiências de luta, dificuldades, conquistas, superações e valorização de uma sabedoria que emana do histórico de interações desses sujeitos com esses lugares, os quais dialogam entre si, por palavras, boletins, músicas, poemas, cordéis ou pelo próprio silêncio e brisas dos redemoinhos, que levam e trazem notícias de todo canto dessa realidade regional.

\section{CONSIDERAÇÕES FINAIS}

Neste artigo, buscou-se desvendar e compreender o semiárido mineiro a partir das experiências de convivência com a seca. Para tal, utilizou-se o Boletim Candeeiro, como fonte de informações sobre

$\begin{array}{llllll}\text { Caminhos de Geografia } & \text { Uberlândia - MG } & \text { v. 19, n. 67 } & \text { Set/2018 } & \text { p. 374-388 } & \text { Página } 385\end{array}$


as práticas e atores sociais, protagonistas de transformações socioeconômicas numa região que outrora era reconhecida como de extrema pobreza. Objetivou-se analisar o discurso do combate à seca no Brasil e mais recentemente, as práticas de convivência no semiárido mineiro, sob o olhar dos conceitos de região e de redes socioterritoriais.

Em termos gerais, a questão regional do semiárido ainda está associada às visões tradicionais ou clássicas quando ainda são reproduzidos discursos que resguardam vestígios ligados a determinações ambientais. O olhar lançado sobre o semiárido ao ser compreendido como uma região homogênea torna-se esgotado e somam-se inúmeras críticas ao desconsiderar os aspectos relativos à ao modo de vida dos habitantes do semiárido. Percebe-se que o discurso do combate à seca postulado nas ações governamentais, revela incoerências, pois o semiárido, no discurso regionalista tradicional, é tomado como uma materialidade fechada, desconsiderando aspectos ligados à biodiversidade e as questões culturais. Assim, reveste-se de importância perceber que a realidade do semiárido, não é somente marcada por características edafo-climáticas limitadas. Antes, porém, devem-se reconhecer as realidades complexas e as respectivas redes de relações estabelecidas entre os sujeitos.

Nesta seara, as análises advindas das experiências relatadas pelo boletim Candeeiro, no contexto de Minas Gerais, trouxeram à tona inúmeras práticas individuais e coletivas envolvendo entidades das mais diversas orientações, em prol do objetivo de conviver com a seca, de forma a resguardar a permanência das famílias rurais assegurando soberania alimentar e desenvolvimento econômico. Ao espacializar as experiências relatadas no Candeeiro, bem como, as entidades governamentais ou não atuantes nesta região, foi possível perceber, o quanto o semiárido mineiro vem se organizando com ou sem o apoio do Estado, delineando redes socioterritoriais que conectam o semiárido de forma ampla.

Em suma, tratar o combate à seca por meio das redes socioterritoriais, é dar luz as imaterialidades que essas articulações ganham. Portanto, essas redes, consistem em mecanismos subversivos para evidenciar que o semiárido é antes de tudo um espaço com lugares e territorialidades distintas, ou seja, composto por dinâmicas socioterritoriais que lhe são peculiares. É imprescindível ultrapassar e romper com a visão limitada ao tratar o semiárido como uma realidade territorial única e abrangente. Deve-se, porém, reconhecer a complexidade das relações ali estabelecidas.

Nesse sentido, o boletim "O Candeeiro", vem iluminando novos caminhos para o desenvolvimento por meio da construção um novo imaginário acerca do semiárido, elaborado por meio do protagonismo dos sujeitos que vivem e convivem com e nesta região. E, são essas articulações formais ou informações que propiciam a realização efetiva desse intercâmbio social, através de alianças e parcerias visando a mobilização popular do semiárido para que essa possa conviver cada vez mais consciente de suas possibilidades com a convivência com a seca.

\section{REFERÊNCIAS}

ASA - Articulação do Semiárido Brasileiro. Declaração do semi-árido: propostas da articulação no semi-árido brasileiro para a convivência com o semi-árido e combate à desertificação. Recife: 26 de Novembro, 1999. Disponível em:

www.mma.gov.br/estruturas/sedr_desertif/_arquivos/declaracao_semiarido.doc. Acesso em: 18 jul. 2017.

ASA BRASIL - Articulação do Semiárido Brasileiro. Acervo: o Candeeiro. 2017. Disponível em: http://www.asabrasil.org.br/acervo/o-candeeiro. Acesso em 18 jul. 2017.

ASSIS, T. R. de P. Sociedade civil e a construção de políticas públicas na região semi-árida brasileira: o caso do Programa Um Milhão de Cisternas Rurais (P1MC). R. Pol. Públ. São Luís, v.16, n.1, p. 179-189, jan./jun. 2012.

CARVALHO, R. V.; LIMA, F. E. S.; SILVA, R. P. O programa um milhão de cisternas (p1mc): uma alternativa de convivência com o semiárido na comunidade agreste de baixo - são miguel/rn.

Caminhos de Geografia, Uberlândia, v.18, n.61, p.136-149, março/2017. Disponível em:

http://www.seer.ufu.br/index.php/caminhosdegeografia/article/view/34601. Acesso em: 26 set. 2017.

CASTELLS, M. A Sociedade em Rede: do Conhecimento à Política. Debates. Imprensa NacionalCasa da Moeda Cortez. p. 17-30, 2006.

\begin{tabular}{llllll}
\hline Caminhos de Geografia & Uberlândia - MG & v. 19, n. 67 & Set/2018 & p. 374-388 & Página 386
\end{tabular}


COELHO NETO, A. S. A trama das redes socioterritoriais no Espaço Sisaleiro da Bahia. Niterói, 2013, 426f. Tese (Doutorado em Geografia) - Instituto de Geociências da Universidade Federal Fluminense, Niterói, 2013.

. Redes sociais, participação social e a territorialidade como componentes de democratização do Ordenamento Territorial. IN: SILVA, O. A; SANTOS, E. M. COELHO NETO, A. S. (Org.). Identidade, Território e Resistência. 1ed.Rio de Janeiro: Consequência, 2014, v. 1, p. 131 145.

CORRÊA, R. L. Espaço, um conceito-chave da Geografia. In: CASTRO, I. E. de; GOMES, P. C. da C.; CORRÊA, R. L. (org.). Geografia: conceitos e temas. Rio de Janeiro: Bertrand do Brasil, 1995.

Região e organização espacial. 7ª edição. São Paulo: Ática, 2003.

Redes Geográficas: reflexões sobre um tema persistente. Cidades, v.9; n.16.

Grupos de Estudos Urbanos. p.199-218. 2011.

FREIRE, A. G.; FALCÃO, F. C. O. Experimentadores: protagonistas da convivência com o semiárido. Agriculturas: experiências em agroecologia, Rio de Janeiro, v. 10, n. 3, p.35-42, set. 2013.

GOMES, P. C. da C. O conceito de região e sua discussão. In: CASTRO, I. E. de; GOMES, P. C. da C.; CORREAA, R. L. (org.). Geografia: conceitos e temas. Rio de Janeiro: Bertrand do Brasil, 1995. GRIGG, D. Regiões, modelos e classes. Boletim Geográfico, 1973.

HAESBAERT, R. Região, Diversidade Territorial e Globalização. UFF. GEOgraphia, Ano. 1, n.1, 1999.

IBGE - Instituto Brasileiro de Geografia e Estatística. Base Cartográfica de Limites Municipais, Estaduais e Federais. Rio de Janeiro: IBGE, 2005.

INCRA - Instituto Nacional de Colonização e Reforma Agrária. Relatório Geral de Assentamentos Superintendência Regional de Minas Gerais. Atualizado em 21/08/2017. Disponível em: http://painel.incra.gov.br/sistemas/index.php. Acesso em: 22 set. 2017.

LENCIONE, S. Perspectivas contemporâneas da Geografia Regional. In: Região e Geografia. Editora Universidade de São Paulo, 1999, p. 175-195.

MAGNANO, A. A. A divisão regional brasileira - uma revisão bibliográfica. DGC/IBGE. Rio de Janeiro, v.57, n.4, p.67-94,1995.

MALVEZZI, R. Semiárido - uma visão holística. 1.ed. Brasília: CONFEA, 2007. 140p. - (Pensar Brasil).

MINÉ, G. O.; RODRIGUES, L. de M. Associativismo quilombola: a luta pelos múltiplos usos do território. In: TUBALDINI, Maria Aparecida dos Santos; GIANASI, Lussandra Martins (Org.).

Agricultura familiar, cultura camponesas e novas territorialidades no Vale do Jequitinhonha: gênero, biodiversidade, patrimônio rural, artesanato e agroecologia. Belo Horizonte, MG: Fino Traço, 2012.

NASCIMENTO, R. da C. Comunicação Popular: uma discussão do Candeeiro nos processos de articulação da ASA e a figura do comunicador popular. In: Congresso Brasileiro de Ciências da Comunicação, XXXIX, 2016, São Paulo. Anais... São Paulo: Sociedade Brasileira de Estudos Interdisciplinares da Comunicação, 2016, p.1-15.

O CANDEEIRO - Boletim Informativo do Programa Uma Terra e Duas Águas. A água e a Reforma Agrária no semiárido mineiro: um romance. Ano 5, no. 91, Agosto, 2011. Varzelândia, Minas Gerais, $2 p$.

Feira Livre de São Francisco - Desafios e conquistas. Ano 6, №. 914, Novembro, 2012. São Francisco, Minas Gerais. 2p.

Assessoria Técnico-Social e Participação Comunitária: Uma Parceria que dá Certo. Ano 6, № 917, Outubro, 2012a. Cônego Marinho, Minas Gerais, 2p.

Saber e amar a terra: para superar a seca, cultivar e criar animais. Ano 7, $\mathrm{n}^{\circ}$ 1072, Novembro, 2013. Matias Cardoso, Minas Gerais. 2p. 
Assentamento Tapera: Uma história de resistência sócio-ambiental, esperança e o constante olhar sob os efeitos das mudanças climáticas. Ano 9, nำ1963, Março, 2015. Riacho dos Machados, Minas Gerais. 4p.

SANTOS, M. Região: globalização e identidade. In: LIMA, L. C. (Org.). Conhecimento e reconhecimento: uma homenagem ao geógrafo cidadão do mundo. Fortaleza: Eduece/LCR, p. 53-64, 2003.

São Paulo: Hucitec, 1996.

Por uma geografia nova: da crítica da geografia a uma geografia crítica.

SOUZA, C. G.; SOUZA, T. A.; SANTOS, F. S. As principais correntes do pensamento geográfico: uma breve discussão da categoria de análise de Lugar. UESB/FTC. Centro Científico Conhecer, n.07, Goiânia, 2009.

Recebido em: 10/10/2017

Aceito para publicação em: 05/06/2018 